\title{
A REVIEW OF CERVICAL FRACTURES AND FRACTURE-DISLOCATIONS WITHOUT HEAD IMPACTS SUSTAINED BY RESTRAINED OCCUPANTS*
}

\author{
Donald F. Huelke, ${ }^{1}$ G. Murray Mackay,${ }^{2}$ Andrew Morris,${ }^{2}$ and \\ MAUREEN BRADFORD ${ }^{3}$
}

\begin{abstract}
${ }^{1}$ University of Michigan Transportation Research Institute, 2901 Baxter, Ann Arbor, MI 48109, U.S.A.;
${ }^{2}$ Accident Research Unit, University of Birmingham, Birmingham, United Kingdom;

${ }^{3}$ Loughborough University, Loughborough, Leicestershire, United Kingdom
\end{abstract}

(Received 3 August 1992; in revised form 5 February 1993)

\begin{abstract}
Crash injury reduction via lap-shoulder belt use has been well documented. Like any other interior car component, lap-shoulder belts may be related to injury in certain crashes. Relatively unknown is the fact that cervical fractures or fracture-dislocations to restrained front seat occupants occur where no head contact was evidenced by both medical records and car inspection. A review of the available literature on car crash injuries revealed more than 100 such cases. A review of the National Accident Severity Study (NASS) 8088 file was also conducted, revealing more examples. Case capsule descriptions from the authors' files are also detailed along with examples of such injuries in infants and children in child restraints. However, cervical fractures or fracture dislocations are rare, as evidenced by the relatively few cases identified in the literature, in the author's files, and by an analysis of NASS 80-90 data that revealed a cervical spine injury frequency of only .4\% at the AIS-3 level (Huelke, Morris, and Mackay 1992).
\end{abstract}

\section{INTRODUCTION}

Injuries to lap-shoulder belted occupants, to any or all body areas, can occur in all types of crash configurations; some of these injuries can be severe. Cervical spine/spinal cord injury sustained by car occupants using lap-shoulder belts have been presented infrequently in the medical or automotive engineering literature. Buried in various articles and reports are individual case histories on this topic. Additionally, biomechanical laboratory testing has shown cervical spine damage in restrained cadavers in frontal-type crash simulations.

This paper reviews most available literature on cervical spine injuries to lap-shoulder belted car occupants, injuries sustained without head impact. Specific unpublished case reports from field crash studies of the investigation teams at the University of Michigan Transportation Research Institute, the University of Birmingham Accident Research Unit,

* Presented at the annual conference of the Association for the Advancement of Automotive Medicine, October 5-7, 1992 , Portland, Oregon. and the Loughborough University Accident Research Unit are presented.

This paper is concerned with the more severe injuries in adults, infants, and children with cervical spine and/or spinal cord injury. This paper is the only compilation known to the authors of cases of non-head impact cervical spine injury sustained in frontal crashes involving adult, lap-shoulder belted passenger car occupants, or infants or children in child safety seats. Reports of cervical spine injuries without head contact from the experimental, medical, and engineering literalure sources are also included.

\section{MATERIALS AND METHODS}

Field crash investigations have been conducted at the University of Michigan and the University of Birmingham (England) since the early to mid-1960s. Since 1983 Loughborough University (England) has also conducted similar investigations. From the files of these data banks, and other cases available to the authors, individual crashes were reviewed on the basis of the following conditions: 
1. Frontal crash only

2. Front seat occupants using lap shoulder belts, infants or children in child safety seats

3. Cervical spine fractures, dislocations and/or spinal cord injury

4. No head impact forehead/face injury

5. Excluding all nonsurvivable types of crashes with extensive car damage as seen in high speed collisions and head injury.

The above criteria were also used in a review of the NASS data for 1980-1989. A search of the medical and engineering literature was also conducted using the same criteria. When the cases were identified, they were scrutinized only for cervical spine injuries where no head impact was reported. In this review more cervical spine fractures with head or face impacts were found (both restrained and unrestrained occupants), but they are not included in this study. Many such head impact-cervical spine injury cases exist in the authors' files as well as in the literature. When there is head impact, it is difficult to identify clearly that the cervical spine injury mechanism was due only to the forward, lateral, or rearward head movement and not associated with head impact on some vehicle interior structure.

When the medical information did not reveal a head injury and vehicle inspection data did not identify a head contact, it was then assumed that no head contact had been made. From the literature review we assumed the information to be accurate.

Whenever possible the Abbreviated Injury Scale (AIS) was used as an indicator of injury severity.

\section{LITERATURE: CRASH CASE HISTORIES-ADULTS}

On review of the medical and engineering literature a surprising number of anecdotal cases were found, frequently "buried" in various reports. Only a few articles were solely directed to the subject of cervical spine/lap-shoulder belted occupants. Also, experimental laboratory results, often published in specific biomechanical reports or in meeting proceedings, not usually known to the medical community, were identified.

Cervical spinal cord injury without evidence of fractures or dislocations have been identified in traumatic, non-head impact events, especially in the higher cervical segments in adults and children (Burke 1974; Cheshire 1977-1978; Dunlap, Morris, and Thompson 1958; Glasauer and Cares 1973; Huelke, Roberts, and Moore 1991; Huelke, Mackay, and Morris 1992a,b; Langwieder and Glaeser 1990; Morres and Appel 1989; Pang and Wilberger 1989;
Papavasilious 1978; Rachesky et al. 1987; Teng and Papatheodorou 1967; Wismans, et al. 1979) or in pedestrians (Farthing 1948; Huelke and Davis 1969; Tharp and Tsongos 1977).

The following are case histories of cervical spine injuries (or anterior neck injuries), to 3-point lap-shoulder belted front seat occupants who did not sustain any head impact in the crash.

Although not directly to the point of this paper, for completeness, we include one of the earliest reports of cervical injury to upper torso restrained occupants presented by Saldeen (1967). In his brief report he presented two drivers who had been decapitated when ejected through open doors; their chins had been caught by the 2-point diagonal shoulder belt. Additionally, Williams and Kirkpatrick (1971) reported on three similar decapitation cases, as did Niederer, Waltz, and Zolinger (1976).

Burke (1973) reported a 60-year-old male driver who became tetraplegic at the $\mathrm{C} 6$ cervical level due to forward subluxation of C6 on C7. Patrick and Andersson (1974) reported a cervical spine fracture of a 12-year-old male restrained in a frontal crash. Epstein, Epstein, and Jones (1978) also reported a C6 fracture of a 20-year-old female. In 1974 Johnson reported a case of a restrained 20-year-old female $(157 \mathrm{~cm}, 45 \mathrm{~kg})$, passenger in a head-on crash, who sustained a fracture of $\mathrm{C} 2$ including the laminae and the pedicles.

Cromack and Zipperman (1975) found three cases of AIS-3 level or greater cervical spine injuries in lap-shoulder belted occupants in an analysis of crash data involving 1973-1975 model cars. Since no other injuries to the individuals were described, it is assumed that the neck injuries occurred without head impact.

Gogler, Athanasiades, and Adomeit (1979) reported a non-head contact, atlanto-occipital dislocation in a 19-year-old, front seat lap-shoulder belted passenger involved in a head-on crash.

Arndt (1975) reported on four cases of individuals who had sustained transverse process fractures at the $\mathrm{C} 7, \mathrm{~T} 1$, or $\mathrm{T} 2$ levels due to the shoulder belt. Taylor, Nade, and Banniser (1976) reported on a 29year-old male driver who sustained anterior lateral subluxation of $\mathrm{C} 5$ on $\mathrm{C} 6$ with crushing of the lateral mass on both sides and lateral displacement. In another case a 25-year-old female driver crashed headon into a telephone pole. She sustained a hangman's fracture of $\mathrm{C} 2$ which was dislocated from the C3 vertebra. No head injuries were reported in either of these cases. Diagonal belt markings were noted across the chest of each.

A British physician (Jefferis, 1976) reported on his own motor vehicle crash. This 69 -year-old male 
driver was wearing a static lap-shoulder belt loosely when his car skidded on wet pavement and went into a ditch. He claims to have hit the steering wheel, cracking his breastbone. He sustained a fracturedislocation of the atlanto-axial joint (C1-C2). Huelke, Sherman, and Murphy (1977) presented a case of a 21-year-old female restrained driver of a VW type of car, who sustained a forward C5/C6 subluxation without head impact.

Walz et al. (1977), using Swiss crash/injury data, reported five non-head contact cervical spine injuries. In their study of underarm positioning of the shoulder belt, States et al. (1987) included a head-on crash involving a 1980 Chevette. Both elderly front seat occupants were killed. The 80-yearold, front right lap-shoulder belted (underarm) passenger $(160 \mathrm{~cm}, 54 \mathrm{~kg})$, sustained a partial dislocation of the atlanto-occipital area. No head trauma was noted at autopsy.

Foret-Bruno et al. (1990) indicated that in their series of 3,781 restrained front seat occupants, there were five $(0.13 \%)$ without head impact who had a neck lesion of AIS 2 or greater.

Rubinstein (1973), in his tabulations of fatal car crashes in which belts were worn, indicated that there were nine cervical spine fractures or dislocations with fatal cord injury. The implication is that there were no other injuries, although this is not clearly stated in the paper.

Dalmotas (1980) summarized findings of a Transport Canada study involving injuries to front seat occupants. Of the 314 fully restrained occupants who received at least one injury $(0.32 \%)$ at the AIS2 or greater injury severity level, there were four occupants $(1.27 \%)$ who had neck injuries where there was no direct evidence of head or neck contact. A fracture of the base of the odontoid process of $\mathrm{C} 2$ was reported in a 65-year-old female, and in another case a 63-year-old male driver fractured a cervical vertebra. The other two cases were not described in detail. Chabannes, Colnet, and Pionchon (1984) reported on 10 cases of $\mathrm{C} 2$ bilateral pedicle fractures in lap-shoulder belted occupants in frontal and near frontal crashes. Most of these did not have any related head injury. Vallet and Ramet (1985) reported on cervical fractures and dislocations and indicated that one of the causes of cervical dislocations is "hyperflexion around seat belt".

Johnstone and Waxman (1987) reported a case of a frontal collision of a 69-year-old, lap-shoulder belted front passenger who sustained a $\mathrm{C} 5 / \mathrm{C} 6$ subluxation along with chest and abdominal injuries. No head/face injuries were reported.

In a review of 251 car crash victims, Tolonen et al. (1984) found 29 front seat victims wearing safety belts, who died of cervical spine injury "in collisions of approximately equal weight vehicle". They determined that 11 (37\%) had the cervical injury from rapid bending of the neck during the maximal deceleration.

Huelke, Mendelsohn, States, and Melvin (1978) showed several examples in different kinds of environments where cervical spine injuries were sustained without head impact. With that report the authors gave case histories of motor vehicle crashes involving cervical spine injuries without head impact. Spontaneous dislocations of the atlas and axis have been reported by Grogono (1954) in non-motor vehicle crashes.

Non-head impact cervical injuries have been reported in other crash environments. Anderson (1988) and Schall (1989) reported on cervical compression fractures to nonejected pilots in high-performance aircraft.

Other reported cervical injuries among 3-point restrained drivers have involved the soft tissues of the neck, the larynx, the subclavian or carotid arteries, and branches of the brachial plexus at the base of the neck (Anderson 1974; Benito, et al. 1990; Clarke and Whittaker, 1980; Costa and Robbs, 1988; DeLorenzo, Mayer, and Gardner, 1991; Ernst, et al. 1988; Guertler, 1988; Niederer et al. 1976; NHTSA 1988; Schwartz et al. 1991; Williams and Kirkpatrick, 1971; Woelfel, et al. 1984). Cervical fractures and/or dislocations, usually at the higher cervical levels, have been reported in pedestrian victims due to torso acceleration inducing neck snapping, in many cases without head impact. (Huelke and Davis 1969; Otte and Rether 1985; Tharp and Tsongos 1977).

\section{LITERATURE REVIEW-CHILDREN}

Numerous authors have reported that cervical spine injuries in children are infrequent, at the $1 \%-4 \%$ level of all spinal injuries that occur in the pediatric population. Agran (1987) indicated that about $21 \%$ of lap-shoulder belted children (aged $10-14$ years) in motor vehicle crashes sustained cervical strain. Restrained children with cervical spine injuries and no head impact have been reported (Conroy and Hall 1987; Diekema and Allen 1988; Fuchs, et al. 1989). A child's body dimensions and his/her proportions are markedly different from those of an adult, and therefore, the child must not be considered a scaled-down adult (Burdi et al. 1969). There has never been a textbook nor reference manual on any biomechanical data or impact tolerance on infants or children, for even basic anthropometric data are scattered and quite difficult to find (Weber, 
Lehman, and Schneider 1985). The elasticity, i.e. the flexibility and mobility of the cervical spine in infants can protect it against injury (Sumchai and Sternback 1991). It has been opined that the disproportionately large head, the weak cervical spine musculature, and ligamentous laxity, can subject the infant to uncontrolled and passive cervical spine movements and possibly to compressive or distraction forces in certain impact deceleration environments. These all contribute to a high incidence of injury to the upper cervical spine as compared to the lower cervical spine are (Burdi et al. 1969; Sumchai and Sternback 1991). The articular facets of the infant and young child are oriented in an even more horizontal direction than in the adult. The cervical spine of young children assumes adult appearance at about 8 years of age when the vertebral bodies become rectangular, the ligaments increase in strength, and the facets become more vertical (Bailey 1952). The "cervicocranium", (base of the skull, $\mathrm{C} 1, \mathrm{C} 2$ and the $\mathrm{C} 2 / \mathrm{C} 3$ disc) is a distinct unit in infants and small children and is considered a specialized area of the cervical spine because of its anatomical difference from the lower, more uniformly shaped cervical vertebrae (Finnigan and McDonald 1982; Glasauer and Cares, 1973; Harris and Edeiken-Monroe, 1987). Using dynamic cervical spine radiographs it has been shown that the fulcrum for flexion is at $\mathrm{C} 2-\mathrm{C} 3$ in infants and young children, at $\mathrm{C} 3-\mathrm{C} 4$ at about age 5 or 6, and at C5-C6 in adults (Baker and Berdon 1966).

In that the skull base, $\mathrm{C} 1$ and $\mathrm{C} 2$ move as a unit in flexion and extension, and to a limited extent in rotation, it is not surprising that anterior displacement of the entire cervicocranial unit can occur after traumatic disruption of the posterior portions of $\mathrm{C} 2$, causing separation of the neural arch ossification centers, stretching of the elastic ligaments or bilateral fractures of the pedicles without evidence of dislocation (Sumchai and Sternback 1991). A distraction force on the cervical spine can pull apart the cervical cartilaginous-osseous structures and associated ligaments and, if in a forward direction, can cause spinal cord damage (Finnigan and McDonald 1982; Tingvall 1987).

It has been reported that pseudosubluxation or physiological anterior displacement of $\mathrm{C} 2$ on $\mathrm{C} 3$ or more than 3 millimeters occurs in approximately $24 \%-33 \%$ of children under 8 years of age (Diekema and Allen 1988; Dunlap et al. 1958; Papavasilious 1978). In autopsy specimens the elastic infantile vertebral bodies and ligaments allow for column elongation of up to 2 inches but the spinal cord ruptures if stretched more than $\frac{1}{4}$ inch (Leventhal 1960). Thus it is difficult to differentiate physiological displace- ment from pathological dislocation of $\mathrm{C} 2$ on $\mathrm{C} 3$ in childhood, especially when an $\mathrm{X}$ ray is taken with the child's head in flexion (Swischuk 1977). Occasionally in young infants there is a reversal of the normal anterior curve, seen in lateral $C$-spine $X$ rays, probably due to the weak, immature cervical musculature (Harris and Edeiken-Monroe 1987). Associated with this, of course, is the normal physiological elasticity of the cervical ligaments, greater than in the adult, allowing for a much greater range of motion of the atlanto-axial joint during flexion and extension. This is evidenced by the extreme head motion of infants or small children as noted in the sleeping child with its "floppy neck" (Fruin and Pirotte, 1977; Fuchs et al. 1989).

\section{CASE HISTORIES}

The following case capsule summaries are from the authors' files at the University of Michigan Transportation Research Institute, University of Birmingham, and Loughborough University.

\section{Adults}

Case 1. A 1977 Ford Mustang crossed the centerline and was involved in an offset, head-on collision with a 1975 Pontiac (Fig. 1). The Mustang driver, a lap-shoulder belted, 25-year-old female $(152 \mathrm{~cm}, 59 \mathrm{~kg})$ had an elongated ecchymotic area across the left shoulder. She sustained a separation of the $\mathrm{C} 1$ and $\mathrm{C} 2$ from $\mathrm{C} 3$. On X-ray review the head and $\mathrm{C} 1 / \mathrm{C} 2$ were noticeably forward of the lower cervical column. In addition, there was a $\mathrm{C} 2$ arch fracture.

Case 2. A 46-year-old male driver in the left front seat, wearing a 3-point restraint system in a 1988 Dodge Shadow, was involved in a collision when another car attempted to make a left turn in front of him. Damage to his car was minor (Fig. 2). The front right, fully restrained, 45-year-old female $(173 \mathrm{~cm}, 73 \mathrm{~kg})$ sustained a fracture of the right C7 transverse process. No head impact was recorded. (UM-2828).

Case 3. A 35 -year-old female $(168 \mathrm{~cm}, 70 \mathrm{~kg})$ was a left front passenger in an Austin Montego involved in a frontal collision with a Ford Capri (Fig. 3). The delta- $V$ calculated to be $24 \mathrm{kph}$. This occupant sustained a fracture to $\mathrm{C} 6$ as well as suffering a loss of sensation on the face, knees, and arm. No head contact was observed. (B5216).

Case 4. A 1985 Renault 5 was hit head-on by a Fiat pulling out from a junction (Fig. 4). The delta$V$ was calculated at $44 \mathrm{kph}$. The Renault driver in the right front seat, (a 64-year-old male, $175 \mathrm{~cm}, 80$ $\mathrm{kg}$ ) suffered bruising to the chest and abdomen as 


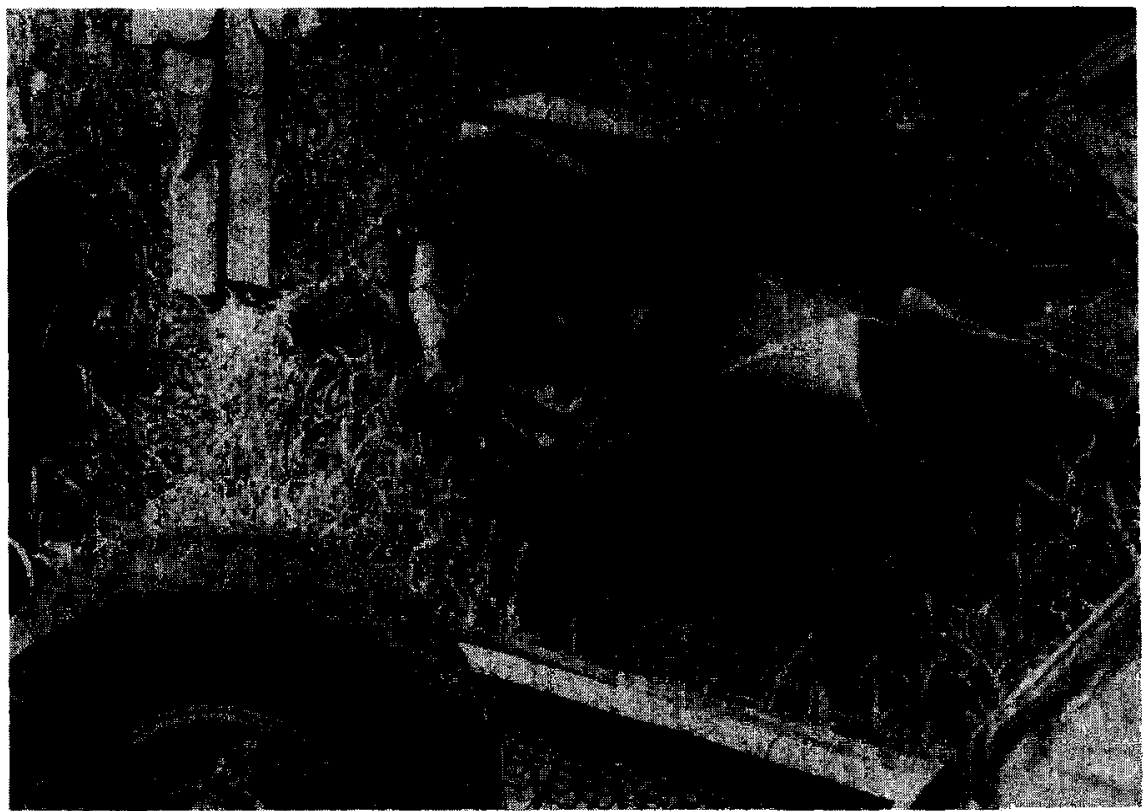

Fig. 1. Frontal crush damage ('77 Mustang). Small female driver wearing a lap-shoulder belt sustained a $\mathrm{C} 2 / \mathrm{C} 3$ separation. No head impact injuries were reported.

a result of seat-belt loading. Additionally, he sustained a bilateral facet dislocation of $\mathrm{C} 6$ on $\mathrm{C} 7$. The injury resulted in tetraplegia at this level which was judged to be permanent. No head contact was observed. The driver suffered from underlying spondylitis which, it is assumed, contributed to the injury. (B5706).
Case 5. A Vauxhall Astra collided with an HGV which was pulled out of a farm entrance (Fig. 5). Maximum crush was $65 \mathrm{~cm}$ and maximum intru$\operatorname{sion} 9 \mathrm{~cm}$ at the left front footwell. Estimated traveling speed was calculated at $31 \mathrm{kph}$. The front right seat passenger, a 91-year-old female, $(150 \mathrm{~cm}, 40$ $\mathrm{kg}$ ) was fatally injured. She sustained a neck fracture

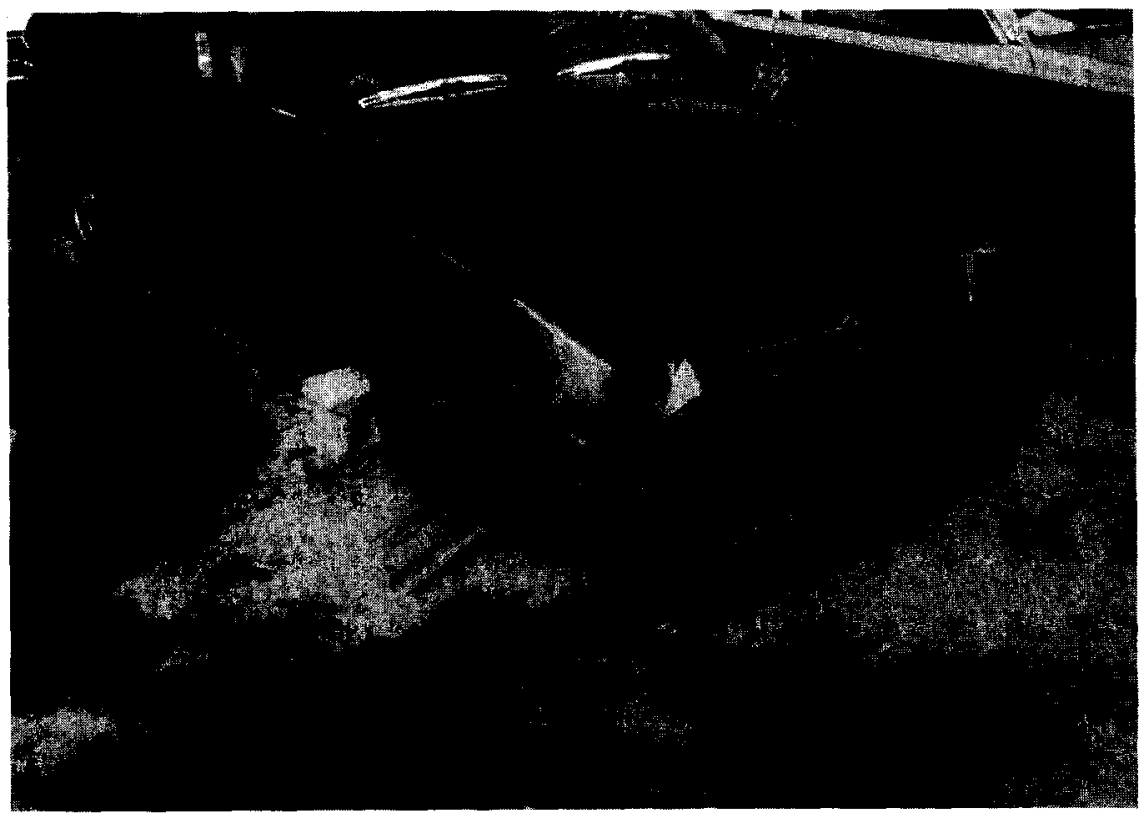

Fig. 2. Minor offset frontal damage ('88 Dodge Shadow). C7 transverse process fracture sustained by the lap-shoulder belted driver. 


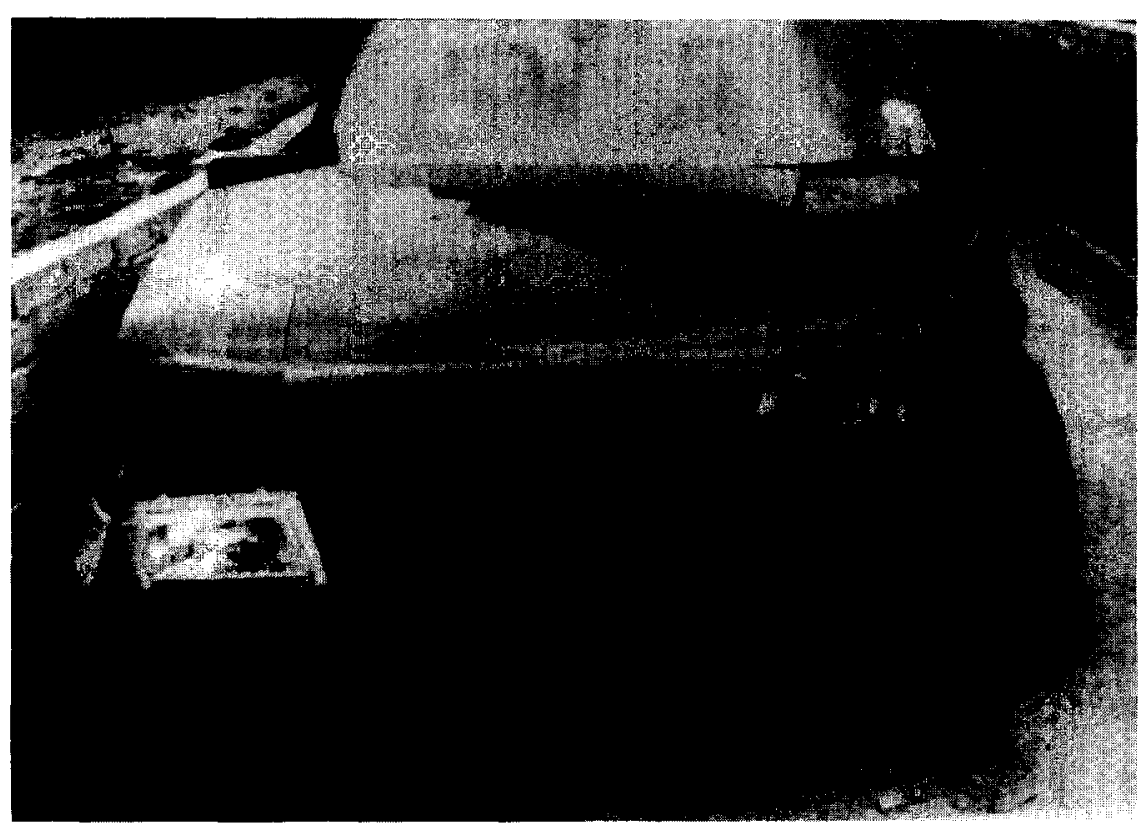

Fig. 3. Non-head contact $\mathrm{C} 6$ fracture sustained by the belted left front passenger. Driver on the right side did not sustain any significant injuries.

at the $\mathrm{C} 4 / \mathrm{C} 5$ level judged to be a noncontact injury. She also sustained serious seat belt injuries including fractured ribs, sternum, a hemothorax, lacerated heart and pericardium, and other cuts and bruises. No head injury was observed. (L1228).

Case 6. A Volvo collided head-on with a Landrover, which lost control and spun on the mo- torway (Fig. 6). Maximum crush was $53 \mathrm{~cm}$ and there was $10 \mathrm{~cm}$ of intrusion at the left footwell. A 44-year-old female, front left seat passenger (height and weight unknown), sustained a fracture to the body of $\mathrm{C} 5$. Other injuries included fractured ribs, fractured talus, and lacerations and bruising. (L137).

Additional low speed crashes involving rela-

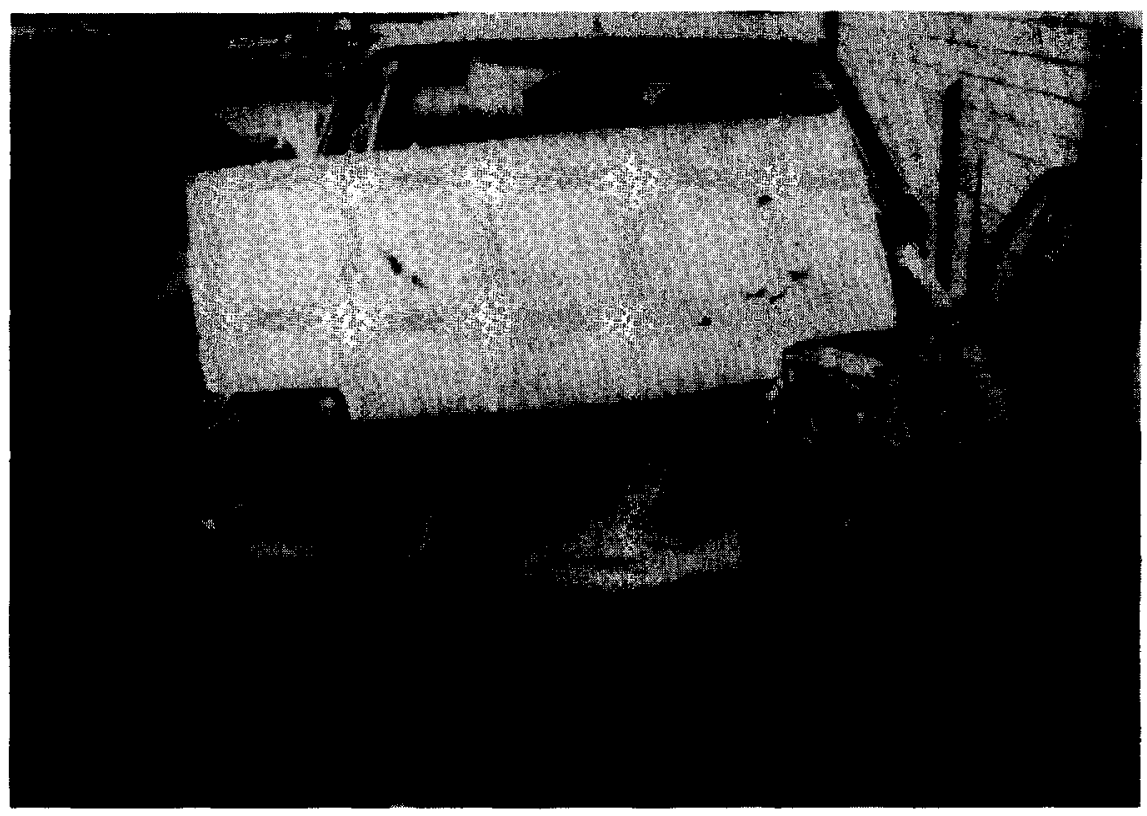

Fig. 4. 1985 Renault 5 involved in a head-on car to car crash. The Renault driver, in the right front seat, sustained a bilateral $\mathrm{C} 6 / \mathrm{C} 7$ dislocation to his spondylothic spine. 


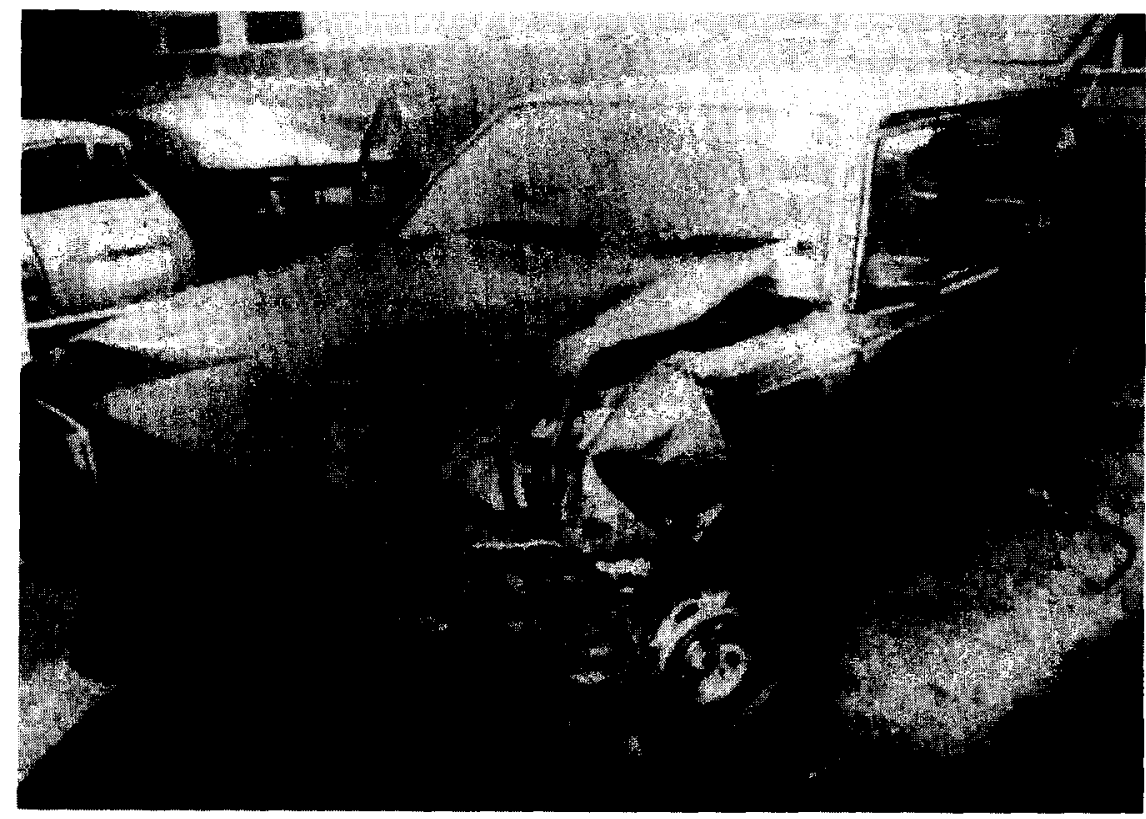

Fig. 5. Passenger side frontal crash. The 91-year-old, female, lap-shoulder belted passenger sustained a C4/C5 noncontact fracture. Multiple belt related injuries were also reported.

tively minor damage were identified with nonhead impact cervical spine fractures or dislocations to belted adult drivers or passengers (Huelke et al. 1992a).

\section{INFANTS AND CHILDREN}

It is likely that in the frontal crashes more infants and children in restraints, child seats, or infant carriers, have sustained cervical spine injuries than are reported in the literature on this subject (Anderson 1988). The following are a few cases taken from the research on crash investigations of the authors and from some published reports.

Case 1. Properly restrained in the front passenger area of a Honda automobile, an 11-month-old female in a 5-point restraint harness child seat, sustained a stretch injury of the cervical cord with no fracture or dislocation of the cervical vertebrae. The child survived and is respirator dependent.

Case 2. In a 5-point harness child seat a 10month-old was a passenger in a Nissan pickup truck involved in a frontal crash. Bilateral shoulder abrasions over the clavicles were noted from the shoulder harness. The child sustained a separation of the spinous process of $\mathrm{C} 1$ and $\mathrm{C} 2$ with ecchymosis on the sides of the base of the neck and adjacent clavicles from the shoulder belts. A severe traction injury to the brain stem and spinal cord was diagnosed. No other injuries were noted.
Case 3. A small child, properly restrained (in a 5-point harness child seat) sustained a high cervical cord stretch injury in a frontal crash.

Case 4. Facing forward in a two-way child seat in the rear of a Volvo 760, a 13-month-old child was fatally injured in a frontal collision. Surface chest bruising under the restraining harness was noted. Postmortem examination revealed a fracture/dislocation of $\mathrm{Cl}$ with crushing of the spinal cord. The only other injury was a $1 \mathrm{~cm}$ superficial cut on the chin (glass) not associated with the cervical injury. No evidence of a head contact was observed. Excess slack was, however, noted in the harness webbing as a result of incorrect routing (the seat padding and seat shell slots were misaligned), and this may have exacerbated the cervical injury.

Case 5. Diekema and Allen (1988) reported on a 10-month-old female who was in a forward-facing child seat in the rear of an automobile involved in a head-on collision. The bilateral bruising under the restraint strap was noted, with the child having no obvious signs of injuries. $X$ ray revealed a subluxation between $\mathrm{Cl}$ and $\mathrm{C} 2$ with a separation of the odontoid process from its cartilaginous attachment of the $\mathrm{C} 2$ body. The odontoid had been moved almost the full anterior-posterior dimension of the C2 body. No neurological damage was reported.

Case 6. Keller and Mosdal (1990) reported a displacement at the $\mathrm{C} 2$ odontoid epiphysis in a 20 - 


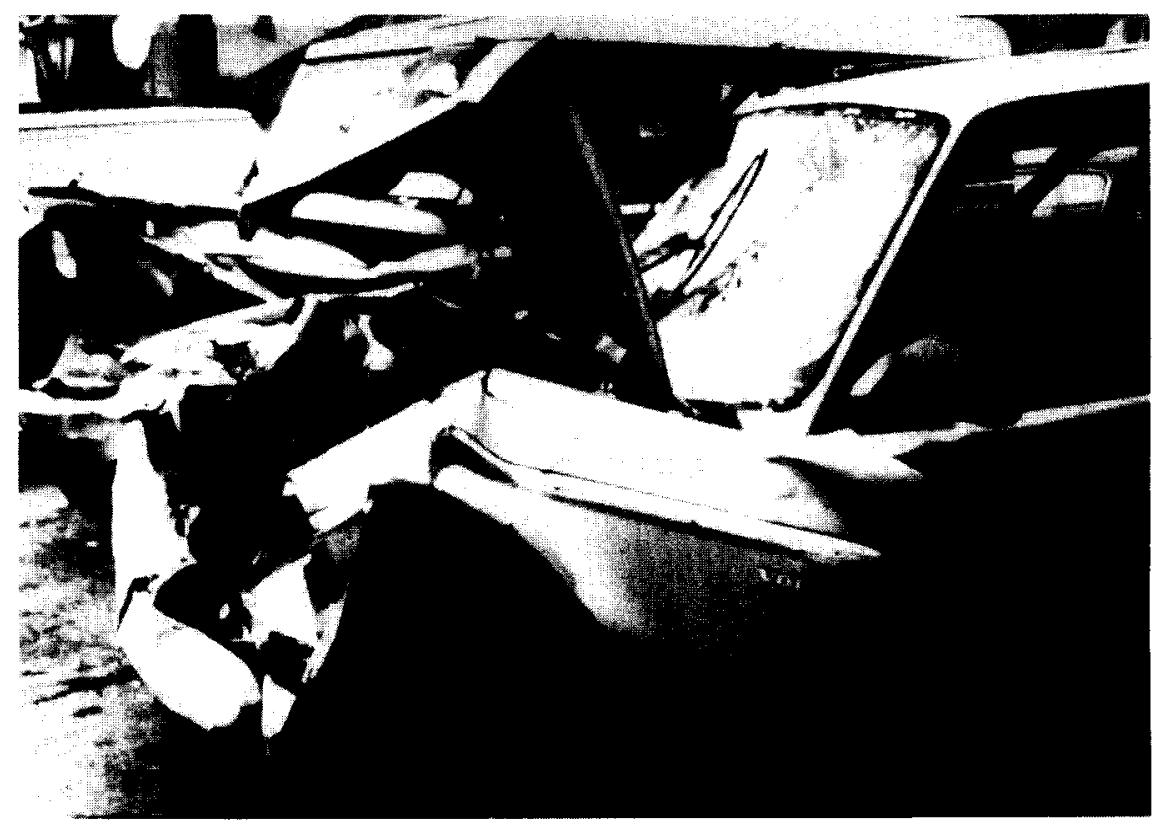

Fig. 6. Offset frontal crash. The female front left passenger had multiple rib fractures from the lap-shoulder belt webbing and a $\mathrm{C} 5$ body fracture without head impact.

month-old female, properly restrained in a child seat, involved in a frontal crash. The front seat restrained parents were not injured.

Cases 7, 8. Langwieder and Hummel (1989) detailed five cases of children restrained in child seats who sustained cervical fractures. Four were in frontal crashes where the car impact was less than 50 $\mathrm{kph}$ "wall type" crash, and one in a side impact. Of these, two of the infants ( 9 months and 12 months of age) had $\mathrm{C} 1 / \mathrm{C} 2$ luxation injuries with quadriplegia. All were in child restraints with 4-point belts, in the rear seat. In the other two frontal cases, it appears that the cervical injuries were not related to any head impacts, although head-face trauma was noted.

Cases 9, 10. Conroy and Hall (1987) presented two cases of children with belt-related injuries. In both cases the child had submarined below the child restraint. Hangman's fracture and a C.2 dens/body fracture were reported.

Case 11. Nevill (1981) reported a rear seat 20month-old child, restrained in a child seat, involved in a head-on collision with both cars traveling at an estimated $40-58 \mathrm{kph}$. No head injury was reported. Total cord transection was noted at C8. No body injury was reported.

\section{NASS CHILD RESTRAINT CASES}

A computer search of the NASS files (1980-1989) did not reveal any cases meeting the criteria of this paper. Only nine children aged 10 years or younger, who had a cervical injury of AIS 3 level or greater, were found. None was in child restraints. Three were lap-belted in the rear seat, and six were unrestrained.

\section{LABORATORY CADAVER STUDIES}

In 1975 Cromack and Zipperman presented the results of simulated $30 \mathrm{mph}$ frontal barrier collisions with five fully restrained unembalmed cadavers. In 3 of 5 of these tests there were cervical fractures in the C4-C5 region with no head impact. Using nine unembalmed cadavers with lap-shoulder belts, Patrick and Levine (1975) found two cases of cervical injury without head impact, one being at the C6 level and the other at $C 7$ level. In the later case there was also a fracture of T4. Both were sustained at a velocity of $40 \mathrm{mph}$ with a stopping distance of 40 inches. No head impact was reported.

Kallieris, et al. (1975) used unembalmed cadavers with 3-point restraint systems with automatic retractors and a sled velocity of $50 \mathrm{~km} / \mathrm{h}$. A total of 31 tests were conducted. At autopsy many of the nonhead impacted cadavers showed ecrvical spine injury as well as injuries as far down as the upper thoracic area. The injuries were ruptures of the discs and ligaments as well as fractures of the various parts of the cervical vertebrae. More recently Kallieris and Schmidt (1990) they found cervical and upper thoracic injuries in simulated crashes using cadavers restrained by a variety of lap-shoulder belts. 
In 1978 research was conducted using six unembalmed cadavers exposed to the simulated rear impact environment that simulated a standard car being struck in the rear at approximately $14 \mathrm{~m} / \mathrm{s}(32 \mathrm{mph})$ (Jones, Bean, and Sweeney 1978). This research at Hollaman Air Force Base revealed that of the six cadavers - three on a seat with a rigid seatback and the others with a deforming seatback-the five cadavers that were equipped with the lap-shoulder belts had lower cervical spine injuries, some of which were due to hyperextension movements of the head over the lowered head support and in other cases from rebound and flexion of the neck forward. In no cases was there a head impact.

Using unembalmed male and female cadavers, Kallieris et al. (1984) ran tests with 3-point belts in use and an additional 109 cadaver tests using the airbag/kneebar system. Numerous cervical injuries were found to the bones, ligaments, and discs at all cervical levels. Additionally, there were upper thoracic, a few lower thoracic, and upper lumbar injuries as well. Similarly, vertebral column injuries were found in the airbag $/$ kneebar tests. There were no head impacts to these restrained cadavers in the impacts. Yang, Cheng, and King (1985) also found three nonsurvivable high cervical injuries in cadaver/airbag experimental impacts.

Foret-Bruno, et al. (1990) reported on 100 cadavers restrained by 3-point belts that were tested in frontal impact at speeds ranging between 50 and $65 \mathrm{~km} / \mathrm{h}$ with mean decelerations of $10-25 \mathrm{G}$. They reported five cervical spine injuries without head impact in 63 nonhead impact tests. Using 2- and 3point belts with and without pretensioners, simulated frontal collisions were conducted at 40,50 , and $65 \mathrm{~km} / \mathrm{h}$ using unembalmed cadavers. In the cervical area tear-drop fractures and fractures of the body were characteristic, with tear-drop fractures found more in the lower cervical spine. Intervertebral disc hemorrhages were noted mainly at C6-C7 to C2-3, interspinal space hemorrhages at $\mathrm{C} 4-\mathrm{C} 5$ to $\mathrm{T} 2$ and joint cavity hemorrhages at $\mathrm{C} 4$ to $\mathrm{T} 2$. Lacerations of the ligamentum flava were noted at $\mathrm{C} 5-\mathrm{C} 7$, and dynamic bending of the head-neck unit was determined to be the cause of these injuries.

Additional cervical fractures or fracture dislocations were noted in cadaver studies by Lange (1971); Kallieris et al. (1990); Burkes, Lawrason, and Peel (1977); and Schmidt et al. (1975).

Surrogates representing children have been used to simulate movements under impact loads and also to attempt to validate dummy models. Some studies are available, but in each the numbers of tests using monkeys or child cadavers are few in number. In the cadaver tests all were in child seats, and some had injuries about or in the cervical spine (Backaitis, et al. 1975; Dejeammes et al. 1984; Kallieris et al. 1976; Schreck and Patrick, 1975; Wismans et al. 1979). Currently some research on child dummy neck improvements and computer simulations of chin-to-chest contacts are being conducted (Janssen et al. 1991).

\section{FREQUENCY OF INJURY}

NASS weighted data, covering a 3-year period (1988-1990), show that in tow-away car accidents a total of 302,588 belted driver and right front passenger occupants experienced head and neck injuries in which head contacts did not occur. Of these, 299,619 occupants sustained neck injuries, mostly of the spine, and 2,969 head injuries. The overwhelming number of the neck injuries were of the noncontact type. These data were analyzed for belted driver and passenger occupants in frontal crashes only. Injuries due to fire and flying glass were excluded. The data indicate that belted occupants in frontal crashes in which head contact did not occur, experienced a total of 111,532 head and neck injuries, of which 221 involved head injuries and 111,311 neck injuries. None of the 221 head injuries exceeded AIS 1 in severity. In contrast, there were 1,363 neck injuries at AIS 2 and above severity. The data thus indicate that head injuries of belted occupants in head noncontact frontal collisions do not extend beyond minor severity level and even at that level constitute only $0.2 \%$ of all head-neck injuries sustained in frontal collisions. Neck injuries at AIS 2 and above severity levels constitute about $1.2 \%$ of all claimed head-neck injuries for those crash conditions and about $0.4 \%$ at AIS 3 and above severity levels.

National injury and fatality estimates are based on projections derived from scientifically sampled tow-away car accidents collected by the National Accident Sample System's primary sampling units in selected geographical areas of the United States. Injury rates in separate accidents may be weighted differently (Gimotty et al. 1980).

\section{DISCUSSION}

The effectiveness of lap-shoulder belts is well known to the medical and engineering community as well as to the public at large. However, restraints of any type, used in any crash configuration, are not the "polio vaccine" for traffic medicine, for there is nothing in the safety armory that will eliminate all motor vehicle deaths and injuries. When all crash types-frontal, side, rear, or rollover-are consid- 
ered, at all impact speeds, belt restraints are effective in reducing the frequency of injuries and deaths. However, any protective device has a limit to its performance and may, of itself, cause injury.

We have noted that minor neck pain (cervical strain) is more frequent to lap-shoulder belted occupants than to unrestrained occupants, a finding reported by others as well (Bunketorp, Romanus, and Kroon 1985; Cromack and Zipperman, 1975; Dalmotas 1980; Gogler, et al. 1979; Huelke and Sherman 1988; Keller and Mosdal 1990; Larder, Twis, and Mackay 1985; Lange 1979; Langwieder, Backaitis, and Fan 1981; Niederer et al. 1976; Oller et al. 1990; Ommaya et al. 1982; Partyka 1983). Burke (1973) noted an overall decrease in the severity of spinal cord damage in the lap-shoulder belted occupants since the compulsory wearing of seatbelts was initiated in his area.

Cervical spine fractures or fracture/dislocation to lap-shoulder belted front seat occupants, who do not have a head impact during the collision phase of the crash, do occur. However, such injuries that have been sporadically reported should in no way mislead one in believing that belts are ineffective or defective. These injuries are infrequent to belt users. The worldwide engineering and medical literature well document the decreases in the frequency of the more severe injuries to lap-shoulder belted front seat occupants.

It appears, in the cases presented above and from the experimental studies, that the 3-point restraints are functioning properly and affording the protection desired. However, the head-neck complex is not restrained, and forward flexion can occur, with the potential for cervical injury. Fortunately, the more severe cervical spine injuries presented are infrequent in occurrence. They occur more often in females and do not appear to be related to anything other than the belt restraint use. No relation was found between such cervical spine injuries and crash severity or various make-models of the passenger cars.

With the above findings and the lower tolerances of the elderly, it may be that older car occupants may more often sustain these types of injuries. Further field investigations of crashes will verify this premise, and such future studies may reveal and identify other injury mechanisms in the elderly. The more severe cervical spine injury, without head impact, to lap-shoulder belted front seat occupants is a relatively rare event as evidenced by this literature and case review. This is probably an indication that for most individuals their tolerances of impact may be higher than in those cases presented, that their vehicle crash delta- $v$ is relatively low, and that none of these is a specific causative factor relative to the cervical spine injury in these restrained occupants.

The injury-reducing benefits of child restraints have been well documented and need not be repeated herc. The low incidence of cervical spine injuries in infants and children is indicated by the fact that no such cases could be found in the extensive NASS crash injury files, they were infrequent in our own crash studies, and there are few reports in the literature.

We believe that the mechanism of the cervical injury reported here is relatively straightforward-head flexion with either a tension or compression component in forward flexion and a relatively restrained torso. Basically, in the frontal type of crash the head continues forward beyond the belted torso. The structure of the child's neck certainly plays a part in the injury. Fuchs et al. (1989) best summarized the reasons for this, including (i) a heavy head on a small body results in high torques being applied to the neck and, consequently, high susceptibility to flexion-extensions injuries; (ii) the lax ligaments that allow a significant degree of spinal mobility (anterior subluxation or up to $4.0 \mathrm{~mm}$ at C2-3 or C3-4 may occur as a normal variant); (iii) the cervical musculature is not fully developed in the infant, thus allowing for unchecked distracting and displacement forces; (iv) the facet joints at $\mathrm{Cl}$ to $\mathrm{C} 3$ are nearly horizontal for the first several years of life allowing for subluxations at relatively little force; (v) immature uncovertebral joints of the $\mathrm{C} 2$ to C4 levels may not withstand flexion-rotation forces; (vi) the fulcrum of cervical movement is located higher in young children (C2-3 level) than in adults (5-6).

There is no obvious explanation why this event does not occur more frequently. It may well be that restrained infants and children are not exposed to the crash forces required to cause the type of cervical injuries described above, for most crashes are of the low level of severity; also anatomic differences between individual infants/children could be an influence on these injuries.

As with any interior car structure, in some specific crashes the adult belt restraint systems, or child restraints, are associated with onc or more injuries to specific body areas. We believe that many times the occupant (child) would have sustained more severe injuries or would have been killed without the use of the restraints. Reduction of the more serious cervical spine injuries may be achieved with an air bag restraint which can reduce the forward head excursion and neck bending in both children and adults (Huelke et al. 1991). 


\section{CONCLUSIONS}

1. Because the head/neck complex of 3-point restrained occupants is untethered, i.e., unrestrained, the cervical spine may be injured due only to inertial forces from the mass of the head acting on the neck.

2. These injuries are due to forward flexion, with or without distraction and with or without some rotation. The specifics of the injuries depend on the way in which the neck is flexed, which in turn depends on the specifics of crash severity, occupant size, age, sitting position and the position of the shoulder belt in relation to the neck and chest, and anatomic differences in the bony and ligamentous strength of the cervical spine.

3 . Given the complexity of the various mechanisms of injury illustrated in these cases and the obviously wide variations throughout the population at risk in susceptibility to injury (due to age, sex, arthritic state, etc.), it is most unlikely that any single parameter such as shear, bending moment, or torsional force can be specified as a tolerance level.

4. With increasing use of restraint systems by both adults and children it is important that the realworld performance and limitations of restraints be monitored, particularly for neck injuries without head contacts, because such injuries are not addressed with the current instrumentation and evaluation techniques available with 1990 s state of the art anthropometric dummies.

5. Head injuries of restrained occupants in frontal collisions in which head contact does not occur are extremely rare. In contrast, neck injuries, while still relatively infrequent, are of significantly higher severity levels. The cervical spine of an unrestrained head-neck complex may be the locus of high force concentrations that result in injury due to inertial forces only.

6 . The rare cervical cord injuries, with or without fractures of dislocations, occur in infants and children without head impact usually at the higher cervical levels. Such injuries almost always occur in children properly restrained in the child seat. The anatomy of the area-large head, lax ligaments, weak cervical muscles, "flat" articular facets all play a role in this injury in infants and children. The mechanism of injury is postulated as inertially induced, due to the forward (flexion) movement of the head with tension or compression forces.

Acknowledgement-The authors thank Stan Backaitis, NHTSA Office of Vehicle Safety Standards, for providing the frequency data from the NASS files.

\section{REFERENCES}

Agran, P. F.; Winn, D. Traumatic injuries among children using lap belts and lap/shoulder belts in motor vehicle collisions. Proc. 31st Am. Assn. for Auto. Med. Des Plaines, IL: AAAM; 1987:283-296.

Anderson, H. T. Neck injury sustained during exposure to high-G forces in the F16B. Aviat. Space Environ. Med. 59(4):356-358; 1988.

Anderson, J. An unusual seat belt injury. Injury 5: 186-187; 1974.

Arndt, R. D. Cervical-thoracic transverse process fracture: Further observations on the seatbelt syndrome. Am. J. Trauma, 15(7):600-602; 1975.

Bailey, D. K. The normal cervical spine in infants and children. Radiology 59:712-719; 1952.

Baker, D. H.; Berdon, W. E. Special trauma problems in children. Radiol. Clin. N. Amer. 4:289-305; 1966.

Benito, M. C.; Garcia, F.; Fernandes-Quero, L.; Lajara, A.; Jardon, E.; Frias, I.; Manzanos, A. Lesion of the internal carotid artery caused by a car safety belt, $J$. Trauma 30:116-117; 1990.

Bunketorp, O.; Romanus, B.; Kroon, P. O. Head and neck injuries in traffic accidents in Goteborg in 1983. Intl. Res. Council on Biokinetics of Impacts/AAAM Conf. on The Biomechanics of Impacts, June, 1985.

Burdi, A. R.; Huelke, D. F.; Snyder, R. G.; Lowrey, G. Infants and children in the adult world of automobile safety design: Pediatric and anatomical considerations for design of child restraints. J. Biomech. 2:267-280; 1969.

Burke, D. C. Spinal cord injuries and seat belts. Med. J. Aust. 2:801-806; 1973.

Burke, D. C. Traumatic spinal paralysis in children. Paraplegia 11:268-276; 1974.

Burkes, J.; Lawrason, G.; Peel, H.; Response to cadaver test subjects in belt restraints. (Final Report) Report no. DOT-HS-802 585. 212 pp. Washington, DC: Department of Transportation; Sept. 1977.

Chabannes, J. ; Colnet, G.; Pionchon, H. Bipedicular fractures of $\mathrm{C} 2$ and safety belts. Neurochirurgie 30: 183-187; 1984.

Cheshire, D. J. E. The paediatric syndrome of traumatic myelopathy without demonstrable vertebral injury. Paraplegia 15:74-85; 1977-1978.

Clarke, P.; Whittaker, M. Traumatic aneurysm of the internal carotid artery and rupture of the duodenum following seat belt injury. Injury 12:158-160; 1980.

Conroy, B. G.; Hall, C. M. Cervical spine fractures and rear car seat restraints. Arch. Dis. Child. 62: 1267-1268; 1987.

Costa, M. C.; Robbs, J. V. Subclavian artery trauma. J. Vasc. Surg. 8:71-75; 1988.

Cromack, J. R.; Zipperman, H. H. Three-point belt induced injuries: A comparison between laboratory surrogates and real world accident victims. Proc. 19th Stapp Conf. San Diego, CA, Nov. 17-19, 1975, 1-24.

Dalmotas, D. J. Mechanism of injury to vehicle occupants restrained by three point scat belts. Proc. 24th Stapp Car Crash Conf., Troy, MI, Oct. 15-17, 1980, 441-476.

Dejeammes, M.; Tarrière, C.; Thomas, C.; Kallieris, D. Exploration of biomechanical data towards a better evaluation of tolerance for children involved in automotive accidents. In: Advances in Belt Restraint Systems: Design, Performance and Usage. Warrendale, PA: SAE; 1984: pp. 427-440. 
DeLorenzo, R. A.; Mayer, D.; Gardner, G. M. Bilateral vocal cord hematomas associated with shoulder harness use. Am. J. Emerg. Med. 9:158-160; 1991.

Diekema, D. S.; Allen, D. B. Odontoid fracture in a child occupying a child restraint seat. Pediatrics 82:117-119; 1988.

Dunlap, J. P.; Morris, M.; Thompson, R. G. Cervical spine injuries in children. J. Bone Joint Surg. 40(A):681-686; 1978.

Epstein, B. S.; Epstein, J. A.; Jones, M. D. Lap-sash three point seat belt fractures of the cervical spine. Spine, 4:189-198; 1978.

Ernst, A.; Robertson, J. J.; Bercier, M. L.; Kline, D. Occult carotid artery injury related to automobile seat belts. Ann. Emerg. Med. 17:1091-1094; 1988.

Farthing, J. W. Atlantocranial dislocation with survival. N. C. Med. J., 9:34-36; 1948.

Finnegan, M. A.; McDonald, H. Hangman's fracture in an infant. Can. Med. Assn. J. 127:1001-1002; 1982.

Foret-Bruno, J. Y.; Tarrière, C.; Le Coz, J. Y.; Got, C.; Guillon, F. Risk of cervical lesions in real-world and simulatcd collisions. Proc. 34th Ann. Mtg. $\Lambda \Lambda \Lambda M .$, Scottsdale, AZ, 1990; 373-389.

Fruin, A. H.; Pirotte, P. P. Traumatic atlantooccipital dislocation. J. Neurosurg. 46:663-668; 1977.

Fuchs, S.; Barthel, J.; Flannery, A. M.; Christoffel, K. Cervical spine fractures sustained by young children in forward-facing car seats. Pediatrics 84:348-354; 1989.

Glasauer, F. E.; Cares, H. L. Biomechanical features of traumatic paraplegia in infancy. J. Trauma $13: 166-170 ; 1973$.

Gimotty, P. A.; Campbell, K. L.; Chiarchavala, T.; Carsten, O., O'Day, J. Final report, statistical analysis of the national crash severity study data. DOT-HS-805561. Washington, D.C.: U.S. Department of Transportation; August 1980.

Gogler, H.; Athanasiades, S.; Adomeit, D. Fatal cervical dislocation related to wearing a seat belt: a case report. Injury 10(3):196-200; 1979.

Grogono, B. J. S. Injuries to the atlas and axis. J. Bone Joint Surg. 36:397-410; 1954.

Guertler, A. T. Blunt laryngeal trauma associated with shoulder harness use. Ann. Emerg. Med. 17(8): 383-839; 1988.

Harris, J. H.; Edeiken-Monroe, B. The radiology of acute cervical spine trauma. Baltimore, MD: Williams \& Wilkins; 1987:pp. 1-10.

Huelke, D. F.; Davis, R. A. A study of pedestrian fatalities in Wayne County, Michigan. HSRI Rept. B109. Ann Arbor, MI: Highway Safety Research Institute, University of Michigan, 1969;1-52.

Huelke, D. F.; Sherman, H. W.; Murphy, M. J. Severe to fatal injuries to lap-shoulder belted car occupants. SAE770149. Warrendale, PA, 1977

Huelke, D. F.; Sherman, H. W. Automatic shoulder belts-injury reduction in Toyota Cressida crashes. SAE 880404. Warrendale, PA:SAE; 1988.

Huelke, D. F.; Mendelsohn, R. A.; States, J. D., Melvin, J. W. Cervical fractures and fracture-dislocations sustained without head impact. J. Trauma 18:533-544; 1978.

Huelke, D. F.; Roberts, J. V.; Moore, J. L. Air bags in crashes: clinical case studies from field investigations. Univ. of Mich. Trans. Res. Inst. 1-11, 1991

Huelke, D. F.; Mackay, G. M.; Morris, A.; Bradford, M. Non-head impact cervical spine injuries in frontal car crashes to lap-shoulder belted occupants. SAE 920560. Warrendale, PA: SAE; 1992a.

Huelke, D. F.; Mackay, G. M.; Morris, A. Car crashes and non-head impact cervical spine injuries in infants and children. SAE 920562. Warrendale, PA:SAE; 1992b.

Janssen, E. G.; Nieboer, J. J.; Vershut, R.; et al. Cervical spine loads to restrained child dummies. Proc. 35th Stapp Car Crash Conf. Warrendale, PA, 1991, 447467.

Jefferis, C. D. An unusual seat-belt injury in a doctor. Injury 7:310-312; 1976.

Johnson, D. H. A case report of cervical spine fracture with lapshoulder belt restraints. J. Am. Coll. Emerg. Phys. 3:31-35; 1974.

Johnstonc, B. R.; Waxman, B. P. Transverse disruption of the abdominal wall-A tell-tale sign of seat belt related hollow viscus injury. N. Z. J. Surg., 57:455-460; 1987.

Jones, A. M.; Bean, S. P.; Sweeney, E. S. Injuries to cadavers resulting from experimental rear impact. J. Forensic Sci. 23:730-744; 1978.

Kallieris, D.; Meister, B.; Schmidt, G. Reaction of the cervical spine during frontal impacts of belt protected cadavers. Proc. 2nd Intern. Conf., Biomechanics of serious trauma. Birmingham, Eng. Sept. 9-11, 1975; 126-142.

Kallieris, D.; Barz, J.; Schmidt, G.; Heess, G.; Matten, R. Comparison between child cadavers and child dummy by using child restraint systems in simulated collisions. Proc. 20th Stapp Car Crash Conf., 1976:511-542.

Kallieris, D.; Mattern, R.; Schmidt T. G.; Worth, D. Kinematic and spinal column injuries in active and passive passenger protection. Intl. IRCOBI Conf. Biomech. of Impact, 1984:279-295.

Kallieris, D.; Schmidt, G. Neck response and injury assessment using cadavers and the US-SID for far-side lateral impacts of rear seat occupants with inboardanchored shoulder belts. Proc. 34th Stapp Car Crash Conf., Warrendale, PA, 1990; 93-99.

Keller, J.; Mosdal, S. Traumatic odontoid eiphysolysis in an infant fixed in a child's car seat. Injury 21:191-192; 1990.

Lange, W. Mechanical and physiological response of the human cervical vertebral column to severe impacts applied to the torso. Symp. on Biodynamic Models and Their Application, 141-167, Wright-Patterson Air Force Base, OH, 1971:141-167.

Langwieder, K.; Backaitis, S. H.; Fan, W.; et al. Compar ative studies of neck injuries of car occupants in frontal collisions in the United States and in the Federal Republic of Germany. Proc. 25th Stapp Car Crash Conf. Warrendale, PA, 1981:71-127.

Langwieder, K.; Hummel, T. Neck injuries to restrained children. 1989 Intl. IRCOBI Conf. on Biomechanics of Impacts Workshop, "Future in Child Restraints", Stockholm, Sweden, Sept. 15, 1989.

Langwieder, K.; Glaeser, P. Protection effects of child restraints-experiences from accidents and sled test with carry-cots. Proc. Road Safety and Traffic Environment in Europe, 140-149, Gothenburg, Sweden, 1990.

Larder, D. R.: Twis, M. K.; Mackay, G. M. Neck injury to car occupants using seat belts. Proc. 34th Am. Assn. for Auto. Med., Washington, D.C., 1985, 153-165. 
Leventhal, H. R. Birth injuries of the spinal cord. J. Pediatr. 56:447-453; 1960.

Morres, H.; Appel, H. Paraplegia as result of unsafe child restraints. 1989 International IRCOBI Conference on the Biomechanics of Impacts Workshop, "Future in Child Restraints", Stockholm, Sweden, Sept. 15, 1989.

Neville, B. G. R. Hyperflexion cervical cord injury in a children's car seat. Lancet 103-104; 1981.

Niederer, P.; Walz, F.; Zolinger, U. Adverse effects of seat belts and causes of belt failures in severe car accidents in Switzerland during 1976. Proc. 21st Stapp Car Crash Conf., Warrendale, PA, 1976, 5593.

NHTSA. Performance of lap/shoulder belts in 167 motor vehicle crashes. NTSB Report No. NTSB/SS-88/03. Washington, DC: NHTSA; 1988.

Oller, D.; Meridith, J.; Rutledge, R.; Thomason, M.; Clancy, T. The relationship between face or skull fractures and cervical spine and spinal cord injuries. A review of 13,834 patients. Proc. 35th A.M. Assoc. Aut. Med. Des Plaines, IL: AAAM; 1991; 315-318.

Ommaya, A. K. ; Backaitis, S.; Fan, W.; Partyka, S. Automotive neck injuries. Ninth Intl. Tech. Conf. on Exper. Safety Vehicles, 1982, 274-278.

Otte, D.; Rether, J. R. Risk and mechanisms of injuries to the cervical spine in traffic accidents. IRCOBI/AAAM Conf. on The Biomechanics of Impacts, Gotehorg, Sweden, 1985; 17-31.

Pang, D.; Wilberger, J. E. Spinal cord injury without radiographic abnormalities in children-The SCIWORA syndrome. J. Trauma, 29:654-664; 1989.

Papavasilious, V. Traumatic subluxation of the cervical spine during childhood. Orthop. Clin. North Am. 9(4):945-954; 1978.

Partyka, S. Whiplash and other inertial force neck injuries in traffic accidents. Washington, DC: National Center for Statistics and Analysis; 1983; pp. 109-127.

Patrick, L. M.; Andersson, A. Three-point harness accident and laboratory data comparison. Proceedings of the 18th Stapp Car Crash Conference, Warrendale, PA, 1974; 201-282.

Patrick, L.M.; Levine, R. S. Injury to unembalmed belted cadavers in simulated collisions. Proc. 19th Stapp Car Crash Conf., Warrendale, PA, 1975;79-115

Rachesky, I.; Boyce, W. T.; Duncan, B.; Bjelland, J.; Sibley, B. Clinical prediction of cervical spine injuries in children. Am. J. Dis. Child., 141:199-201; 1987.

Rubinstein, E. An analysis of fatal car crashes in which the victim was wearing a seatbelt. Proc. Intl. Conf. Biokinetics of Impacts, Lyon, France, May 25, 1973; $49-57$.

Saldeen, T. Fatal neck injuries caused by use of diagonal safety belts. J. Trauma, 7(6):856-862; 1967.

Schall, D. G. Non-ejection neck injuries in high performance aircraft. ADARD Conf. Proc. 471:2-1/10, 1989.

Schmidt, G. ; Kallieris, D. ; Barz, J.; et al. Neck and thorax tolerance levels of belt-protected occupants in head-on collisions. Proc. 19th Stapp Car Crash Conf. 225-257, Warrendale, P $\Lambda, 1975$

Schreck, R. M.; Patrick, L. M. Frontal crash evaluation tests of a five-point harness child restraint. Proc. 19th
Stapp Car Crash Conf., Warrendale, PA, 1975, 317-343.

Schwartz, N.; Buchinger, W.; Gaudernak, T.; Russe, F.; Zechner, $W$. Injuries to the cervical spine causing vertebral artery trauma: case reports. J. Trauma, 31(1):127-133; 1991

Stalnaker, R.; Medlin, J. W.; Vladislav, G.; et al. Performance evaluation of child dummies and baboons in child restraint systems in a systematized crash environment. Proc. 19th Stapp Car Crash Conf., Warrendale, PA, 1975:345-403.

States, J. D.; Huelke, D. F.; Dance, M.; Green, R. Fatal injuries caused by underarm use of shoulder belts. $J$. Trauma, 27(7):740-745; 1987.

Sumchai, A. P.; Sternback, G. L. Hangman's fracture in a 7-week old infant. Ann. Emerg. Med. 20(1): $1991 ; 86-89$.

Swischuk, L. E. Anterior displacement of $\mathrm{C}_{2}$ in children: Physiologic or pathologic? Pediatr. Radiol. $122: 759-763 ; 1977$.

Taylor, T. K. F.; Nade, S.; Banniser, J. H. Seat belt fractures of the cervical spine. J. Bone Joint Surg. 58B:328-331; 1976.

Teng, P.; Papatheodorou, C. Traumatic subluxation of $\mathrm{C}_{2}$ in young children. Bull. Los Angeles Neurol. Soc. 32:197-202; 1967.

Tharp, K. J. ; Tsongos, N. G. Injury severity factors-traffic pedestrian collisions. SAE 770093. SAE International Congress; Detroit, MI, Feb, 28-Mar. 4, 1977.

Tingvall, C. Injuries to restrained children in cars involved in traffic accidents. Acta Paediatr. Scand. Supplement 339:III:1-15; 1987.

Tolonen, J.; Kiuiluto, O.; Santauirta, S.; Slatis, P. The effects of vehicle mass, speed and safety belt wearing on the causes of death in road traffic accidents. Ann. Chir. et Gyn. 73:14-20; 1984.

Vallet, G.; Ramet, M. Frequency and severity of head and neck injuries as a function of types of traffic users. IRCOBI/AAAM Conference on The Biomechanics of Impacts, Goteborg, Sweden, 1985; 71-89.

Walz, F.; Niederer, P.; Zollinger, U.; Renfer, A. Analysis of 115 killed and 205 severely injured (OAIS $\geqq$ ) seat belt users. Proc. 6th Intl. Conf. Int. Assn. Acc. and Traffic Med., Melbourne, Aust., 1977.

Weber, K.; Lehman, K. J.; Schneider, L. W. Child anthropometry for restraint system design. UMTRI-85-23. Ann Arbor, MI: University of Michigan; 1985; $24 \mathrm{pp}$.

Williams, J. S.; Kirkpatrick, J. R. The nature of seat belt injuries. J. Trauma 11(3):207-218; 1971 .

Wismans, J.; Maltha, J.; Melvin, J. W.; et al. Child restraint evaluation by experimental and mathematical simulation. Proc 23rd Stapp Car Crash Conf., Warrendale, PA, 1979, 382-415.

Woelfel, G. F.; Moore, E. E.; Cogbill, T. H.; Van Way, C. Severe thoracic and abdominal injuries associated with lap-harness seatbelts. J. Trauma, 24(2): $166-167 ; 1984$.

Yang, K. H.; Cheng, R.; King, A. I. Neck luads in frontal impact. 13th Intl. Workshop on Human Subjects for Biomechanical Research, 71-77, Arlington, VA, 1985. 